\title{
How covid-19 has highlighted the importance of design as well as price in the NHS supply chain
}

To get the safest-and not just the cheapest-devices, the NHS needs to start taking ergonomics
seriously, experts say. The pandemic may finally have made the argument, reports Jane Feinmann

\section{Jane Feinmann journalist}

In March 2020, the UK government commissioned non-medical manufacturers, including Dyson and Renault, to produce ventilators for the excess number of patients expected to have respiratory failure as a result of covid-19. Because the machines would be used by non-specialist clinicians during the pandemic, NHS England commissioned guidance ${ }^{1}$ on ergonomic (also known as human factors) design of the ventilators, aimed at achieving "optimum human safety and performance."

"Following consultation with our expert members, we produced the guidance and sent it off within 48 hours," says Noorzaman Rashid, chief executive of the Chartered Institute of Ergonomics and Human Factors (CIEHF). The Medicines and Healthcare Products Regulatory Agency (MHRA) then sent this guidance to manufacturers.

It sounds like common sense: for more than 20 years, human error has been recognised as a leading cause of patient harm and death in healthcare. ${ }^{2}$ The first report calling for ergonomic design of healthcare products-to make it more difficult for healthcare practitioners to make mistakes-was published by the Cambridge Design Centre in 2004. ${ }^{3}$ Design for Patient Safety was commissioned by England's then chief medical officer, Liam Donaldson, as a response to the Bristol Royal Infirmary scandal.

It described a proactive approach to healthcare devices, "providing the basis to design flaws out of the system before they result in needless tragedies," says lead author John Clarkson, professor of engineering at the University of Cambridge. As recognition of ergonomic design grew, Clarkson co-authored a further report, published in 2017: Engineering Better Care was the result of a collaboration between the Royal College of Physicians, the Academy of Medical Sciences, and the Royal Academy of Engineering. ${ }^{4}$

Yet the commissioning of the ventilator guidance remains an exception rather than the rule. And a book to be published later this year claims that clinicians-most notoriously Hadiza Bawa-Garba at Leicester Royal Infirmary and Jane Barton at Gosport Memorial Hospital-often take the blame for harm to patients while the contribution of poorly designed medical technology is ignored or underestimated.

There are, however, signs that the NHS is starting to take human factors seriously-and covid-19 is a driver.

\section{DIY assessment}

It remains unusual for purchasing teams to be given the information needed to make an ergonomic assessment of devices on the market. When Northampton General Hospital planned to replace all its infusion pumps three years ago, it had to commission its own independent human factors assessment to find which of four devices, all with CE marks certifying European standards for health, safety, and environmental protection, would be the safest.

"With medical devices, especially those that are prone to error, it's not enough that a device has got a CE mark-because there is huge variation in the ergonomic standards of the products available," says Chris Frerk, consultant anaesthetist at Northampton Hospital. "We needed the equivalent of a Which? guide so that the hospital could put those with the lowest risk of error into clinical practice."

Frerk convinced the hospital that it was worth commissioning an assessment of the infusion pumps. "These machines are prone to error while treating many of the sickest patients with carefully titrated doses of insulin, heparin, and intravenous antibiotics, among other treatments," he told The BMJ. A team of ergonomic experts rated the pumps on a 10 point safety scale for different settings from intensive care units and operating theatres to general wards.

"Information about potential usability problems is available to companies and ergonomic experts but not to the purchasers," Frerk says. "We can't expect medical device manufacturers to tell us about flaws in their devices voluntarily. But nor can we, as end users, be experts about the unintended consequences of design problems."

Anecdotally, the assessment appears to have been worthwhile. "Since introducing the new pumps and infusion devices, there has been a decrease in the number of incidents that doctors and nurses are reporting," Frerk says.

Harold Thimbleby, a digital health fellow at Swansea University, carried out the assessment for Northampton free. He is also the author of the upcoming book Fix IT, How to Solve the Mess of Digital Healthcare, which argues that lengthy investigations of health scandals often ignore evidence on unreliable devices (see box).

Thimbleby says the NHS must face up to the potential unreliability of equipment. "If it's scapegoated away 
as the user's fault, then the system needn't change and things carry on as before," he says.

\section{Price versus performance}

A reorganisation of NHS Supply Chain, including the setting up of the Procurement Transformation Programme in 2018, required procurement teams to ensure that its products "meet the needs of users including patients and health and care professionals."

The key objective of the new model, however, is "to harness the spending power of the NHS across acute, community, and home care customers, delivering €2.4bn (€2.7bn; \$3.1bn) in savings directly to NHS trusts over a five year period," explained supply chain coordination chief executive Jin Sahota in November 2019. ${ }^{5}$ To achieve this, there would be "a relentless approach to create value and gain competitive advantage."6

The fact that an integral part of NHS policy is to save money on products by buying at the best possible price is a major obstacle to change, says Clarkson.

"NHS England wants improvement, but good design can come second. There won't be change if the job of a procurement team is to find the cheapest device. And that won't change without a new, more holistic mindset at a higher level," he says.

So far, NHS Supply Chain has put the onus on clinicians to complain to its customer service department if a device is identified as unsafe. NHS Supply Chain's product assurance specialist, Colette Longstaffe, told a conference last year that it was feedback from users that would help it ensure that healthcare devices are safe.

\section{Pandemic pushing change}

There are now increasing signs that the pandemic is forcing change-with the NHS finally taking ergonomics seriously. As well as the unprecedented pre-production ventilator specification, the Clinical Human Factors Group (CHFG) has produced a guide for NHS procurement teams, Selecting Safe and Easy to Use Products for Healthcare, ${ }^{7}$ to introduce human factors into procurement instead of purely price based purchasing.

The guide was a response to the "concern of the MHRA about the growing number of medical devices and errors in use," explains the guide's author, the CHFG's ergonomic specialist Jo Simmons. "It was to be published later this year but we brought it out early because these concerns have been amplified by the pandemic."

Retired ear, nose, and throat surgeon John Pickles, CHFG chair, told The BMJ, "With covid-19, healthcare professionals are more likely to be working in stressful conditions, often in an unfamiliar environment, with changing working practices and without supervision. It makes it more important that healthcare procurement teams ensure that high risk devices and equipment are ergonomic and not just the cheapest ones that work.”

NHS Supply Chain has welcomed the guide, and Longstaffe told The BMJ that its teams are continually working with its procurement companies "to drive quality and ensure that human factors are included during the design and tender specifications where possible."

Covid-19 has "definitely had an impact on the way people are thinking about ergonomic healthcare devices within the NHS and there is now a greater recognition of the importance of human factors than before the pandemic," Rashid says.

\section{Solutions}

So how might progress be made? Local initiatives such as the one at Northampton can have only limited success under the current system, Allan Rivans, head of procurement at Northampton, says. The assessment carried out by Thimbleby "highlighted the matter of colour coding and the impact on those that are colour blind, something I had not considered-and this has stuck with me," says Rivans. "Has it influenced my thinking? Yes. Has it influenced other procurements? Less so given more and more procurement is undertaken centrally."

CHFG envisages an important national role for NHS Supply Chain in evaluating higher risk products-taking into account the psychological and physical profiles of potential users and the specific tasks that they will be expected to carry out. "We would like to see NHS Supply Chain assessing higher risk products such as syringe drivers and reporting on the 'best in class' to underpin hospital procurement," says Simmons.

There are other initiatives. CIEHF has just published a guide to track learning from covid $-19 .{ }^{8}$ Later this year, it is to publish a learning pathway to support NHS staff-including doctors-to become accredited human factors practitioners.

A further move could be to introduce pre-launch testing of new devices "in the same way as drugs are," says Thimbleby.

"Alternatively, they could be put on the market without tests, provided they collect good data on their performance and patient outcomes over a year and be certified for general use once they've shown they are adequately successful.”

In the event, the UK government's ventilator order was cancelled in April and CIEHF pre-production ergonomic specification for ventilators was never widely used. Clarkson nonetheless sees it as reason for optimism. "We have to hope that people will recognise that ventilators designed to this specification would have been ergonomically superior and we can learn much from such guidance," he told The BMJ.

"We need people from all disciplines to have a passion to get good design into health. Above all we need the help of doctors who understand why this is important."

\section{Clinicians scapegoated: Bawa-Garba and Gosport}

"Unfortunately for doctors, we think that technology is extremely reliable, so when things go wrong it must be the user's fault-that surely the doctor or nurse was inattentive," says Harold Thimbleby, author of the book Fix IT, How to Solve the Mess of Digital Healthcare, to be published later this year.

"We prefer this simple human story of betrayal by a bad person to the hard work of investigating system problems."

Thus Hadiza Bawa-Garba at Leicester Royal Infirmary (along with two nurses) was indicted for gross negligence manslaughter following the death of a six year old child in 2011-while the contribution of a defective computer system was ignored. "In the mass of discussion about this controversial case I haven't found any mention of improving the hospital IT systems," Thimbleby told The BMJ.

"Yet everybody depends on reliable digital systems and when they fail so badly that they contribute to manslaughter, one would expect some public acknowledgement and serious effort to improve them."

He describes a similar lack of curiosity in the role of the "cost effective" Graseby syringe drivers in use at the Gosport Memorial Hospital where 456 patients died of opioid overdose between 1989 and 2000. Retired doctor, Jane Barton, could still face murder charges for "presiding over an institutionalised regime which had a flagrant disregard for human life." 9 
Yet the potential charges ignore the hospital's persistent and unmonitored use of syringe drivers (devices providing continuous subcutaneous infusion) that were "less safe but cheaper, with inadequate alarms and no internal memory." The use of drivers using different methods of measuring drug doses on the same ward, even on the same patient, "made errors easy," says Thimbleby.

These were the subject of "one of the biggest cover-ups in NHS history," according to a whistleblower member of the inquiry. ${ }^{10}$ It took 25 years from the start of the Gosport tragedy before the NHS finally ruled in June 2018 that the Graseby syringe drivers were unsafe and should be banned.

Commissioned, not externally peer reviewed.

1 Chartered Institute of Ergonomics and Human Factors. Human factors in the design and operation of ventilators for covid-19. www.ergonomics.org.uk/common/Uploaded\%20files/HF_in_Design_of_Ventilators_FinaL_01April.pdf.

2 Grol R, Baker R, Moss F. Quality improvement research: understanding the science of change in health care. Qual Saf Health Care 2002;11:110-1. doi: 10.1136/qhc.11.2.110 pmid: 12448794

3 Robens Centre for Health Ergonomics, Helen Hamlyn Research Centre, Cambridge Engineering Design Centre. Design for patient safety. 2004. www-edc.eng.cam.ac.uk/downloads/designforpatientsafety.pdf.

4 Royal Academy of Engineering. Engineering better care. www.raeng.org.uk/policy/publications/interactives/engineering-better-care.

5 National Health Executive. How the new NHS Supply Chain is transforming the landscape. 27 November 2019. www.nationalhealthexecutive.com/Health-Service-Focus/how-the-new-nhssupply-chain-is-transforming-the-landscape.

$6 \quad$ NHS Supply Chain. Supply Chain Coordination Limited. www.sccl.nhs.uk.

7 Clinical Human Factors Group. Selecting safe and easier to use products for healthcare using human factors specification and checklists. https://chfg.org/selecting-safe-and-easier-to-useproducts-for-healthcare.

8 Chartered Institute of Ergonomics and Human Factors. Achieving sustainable change: capturing lessons from covid-19. July 2020. https://ergonomics.org.uk/Common/Uploaded\%20files/Publications/Sustainable-Change/CIEHF-Achieving-Sustainable-Change.pdf.

9 Gosport Independent Panel. Panel report. www.gosportpanel.independent.gov.uk/media/documents/070618_CCS20.

10 Ward V. Gosport inquiry panel accused of "NHS cover up" over faulty syringe drivers. 23 June 208. www.telegraph.co.uk/news/2018/06/23/gosport-inquiry-panel-accused-nhs-cover-faultysyringe-drivers. 